\title{
A Metadata Model Proposal for Simulation Based E-learning
}

\author{
https://doi.org/10.3991/ijes.v5i1.6349 \\ El Hassan Laaziz \\ Hassan $1{ }^{\text {st }}$ University, Settat, Morocco \\ laaziz02@gmail.com \\ Elmustapha Elkhouzai \\ Hassan $1^{\text {st }}$ University, Settat, Morocco \\ elkhouzai_m@yahoo.fr
}

\begin{abstract}
Existing E-learning standards and specifications present a great basis for the development of E-learning, on line and distance learning contents that are accessible, interoperable, durable and reusable. E-learning contents are supported by these standards as well as by the LMS (Learning Management System) or web technologies compliant to them. However, simulation based contents or learning objects are less integrated in the E-learning contents than other learning objects, partially because standards and specification don't pay much attention to more specify them in term of metadata requirements.

The main objective of this paper is the elaboration of a new Metadata model on the basis of Learning Object Metadata (LOM) with a wider scope that could support more easily simulation objects, especially in experiential E-learning content in which simulation activity should be executed by the learner, monitored and tracked by the tutor completely on the LMS.
\end{abstract}

Keywords-E-Learning; content; metadata; LOM; simulation; Constructivism.

\section{Introduction}

During last decade, there were a growing interest of consortia and E- learning community, to e-learning contents integrating simulation as a learning activity. Learning contents based on simulation; either as the main learning activity or as a training supplement; are widely used [1]. The existing literature on simulation based learning activity, considers it to have a great ability to transfer skills into real-life and job situations and to produce positive learning outcomes, compared to other learning activities. In some engineering and technical higher education fields, as well as in high risk workplace training (medical, nursing and aviation), simulation based e-learning contents are considered to be the most cost effective to acquire transferable skills. Elearning contents nowadays are used in almost all higher education and workplace training fields. First generation e-learning is past the market creation phase and well into a value creation phase [2]. However, contributions on Simulation based e- 
learning contents are mainly focusing on simulation as the core content using either a simulator or a game generally running out of the LMS (Learning Management System) environment. There are very few contributions and integrated learning models containing simulation activities completely running on LMS execution environment.

The main objective of this paper is the elaboration of a new Metadata model on the basis of Learning Object Metadata of IEEE (LOM) with a wider scope that could support more easily simulation objects, especially in experiential E-learning content in which simulation activity should be executed by the learner, monitored and tracked by the tutor completely on the LMS.

In the following, we will first review the existing literature in terms of simulation usage in higher education and E-Learning contents standards and specification. We focus on the de-facto standard LOM and its assessment in term of coverage. In the second part, we will then present our Metadata model that is an update of LOM.

\section{$2 \quad$ Litterature review}

\subsection{Simulation based learning activity}

Embedding Simulation is a combination of information technology (simulation software or computer program) and a modeling activity to model a real life system, in order to validate decisions affecting the real life system. This enables the trainee to try out different ways of operating the system by changing system parameters, event occurrence laws and even the structure of the system without experiencing the real life system [1]. Simulation is grounded on action learning. Its underlying discipline is arguably the foundation of most everything we learn: experiential learning. While individuals may each perceive information through their senses, people ultimately learn by doing [3].

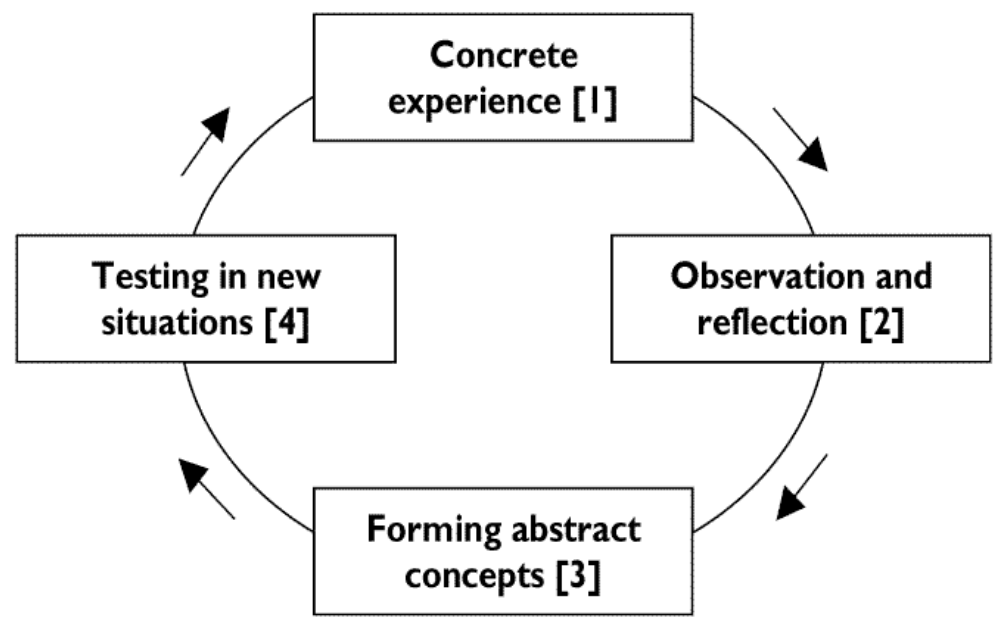

Fig. 1. Experiential Learning [3] 
In higher technical and engineering education fields where the experiential learning is adopted, simulation is frequently used as learning activity either for class courses and e-learning contents. It is used as a learning activity to transfer decision making skills. Decision making; not only on simulated real system behaviour (to be planed, monitored and controlled) in real life; but also on real system design in both static and dynamic points of view. Less frequently, Simulation is used in almost all training and education maybe because of the availability of compliant simulation tools and software but also because of the variety of skills to transfer in those areas [1].

There are different levels of Simulations that are characterized by their level of complexity. There are mainly tree levels: one-shot simulations, learn-by-example simulations, and microworlds [4]:

- One-shot simulations. For a simulation of a complex system, learners make changes to many different settings and see the results immediately. Learners can adjust and refine their responses as they want. One-shot simulations are designed for courses that can be taken in one time basis.

- Learn-by-example simulations: learners are involved in incidents to determine the course of events, make decisions at key moments and observe the consequences. At the end, learners are encouraged to summarize what they have learned. These simulations are often easy to implement and require little programming, just a cleaver link HTML pages [4].

- Microworlds: provides a simplified representation of a physical environment where objects react to each other and to the learner as defined principles which allow complex behaviors arise. Microworlds are an effective way to teach highly complex activities that cannot be reduced to a few simple principles. They are complex to design and build and require knowledge of the simulated environment [4].

Brandon, 2002 [2], suggest the Simulation comparative characteristics shown in Table 1.

\subsection{Simulation integration in E-learning contents}

During last decades, E-learning contents (but also on line courses generally) were produced more and more sophistically following the breakthroughs in information technologies development. Multimedia, Learning Management Systems (LMS), Internet and mobile communication devices are the most influent ones on E-learning. The multiplication of the supporting technologies, their wide use and abundance of contents productions made it necessary to standardize these contents in terms of learning units (or learning objects) and structure. Initiatives and efforts of recognized organizations and consortia (Dublin Core ${ }^{1}, \mathrm{ARIADNE}^{2}, \mathrm{IMS}^{3}$ and $\mathrm{ADL}^{4} \ldots$ ) are continuing to formalize reference models and standards for E-learning contents and lear-

\footnotetext{
http://www.dublincore.org

$2 \mathrm{http}: / /$ www.ariadne-eu.org

${ }^{3} \mathrm{http}: / /$ www.imsglobal.org

${ }^{4} \mathrm{http}: / /$ www.adlnet.org
} 
Table 1. Simulation comparative characteristics/features [2].

\begin{tabular}{|c|c|}
\hline characteristics/features & description/examples \\
\hline offering type & $\begin{array}{l}\text { - } \text { simulation development tools for customers to create their own simulations } \\
\text { - pre-built, off-the-shelf simulation with parameters that can be modified by } \\
\text { customers for their specific needs } \\
\text { - } \text { pre-built, off-the-shelf simulation that cannot be modified } \\
\text { customized }\end{array}$ \\
\hline simulation category & $\begin{array}{l}\text { - } \text { business simulations } \\
\text { - } \\
\text { - } \\
\text { proceduational simulations } \\
\text { etc. }\end{array}$ \\
\hline simulation level & $\begin{array}{ll}\text { - } & \text { one-shot } \\
\text { - } & \text { learn by example } \\
\text { - } & \text { microworld }\end{array}$ \\
\hline compliancy & $\begin{array}{ll}\text { - } & \text { AICC } \\
\text { - } & \text { SCORM } \\
\end{array}$ \\
\hline $\begin{array}{l}\text { bookmarking with the } \\
\text { simulation }\end{array}$ & learner can bookmark his/her place in the simulation and return at a later time \\
\hline $\begin{array}{l}\text { built-in performance } \\
\text { tracking }\end{array}$ & simulation tracks everything the learner does while engaged in the simulation \\
\hline $\begin{array}{lrr}\text { works } & \text { w/ } & \text { LMSs } \\
\text { (Learning } & \text { Management } \\
\text { Systems) } & \end{array}$ & tested and interoperable with third-arty LMS tools \\
\hline cross-platform support & $\begin{array}{ll}\cdot & \mathrm{PC} \\
\cdot & \mathrm{MAC} \\
\end{array}$ \\
\hline company information & $\begin{array}{ll} & \text { number of employees } \\
\text { - } & \text { years in service } \\
\end{array}$ \\
\hline product information & $\begin{array}{ll} & \text { number of clients using product } \\
- & \text { year originally released (version } 1.0 \text { ) } \\
\end{array}$ \\
\hline interactive capabilities & $\begin{array}{l}\text { - } \text { feedback } \\
\text { - } \text { assessments } \\
\text { - } \text { coaching } \\
\text { directed to references } \\
\end{array}$ \\
\hline system requirements & $\begin{array}{ll}\text { - } & \text { for the learner } \\
\text { - } & \text { software and hardware requirements for the server }\end{array}$ \\
\hline target audience & $\begin{array}{ll}\cdot & \text { technical level } \\
\cdot & \text { management level } \\
\text { - } & \text { etc. }\end{array}$ \\
\hline pricing information & $\begin{array}{ll}\cdot & \text { customize } \\
\text { - } & \text { off-the-shelf } \\
\text { - } & \text { license } \\
\text { - } & \text { per user vs. per course } \\
\end{array}$ \\
\hline product support & $\begin{array}{ll} & 24 / 7 \\
- & \text { additional cost? } \\
\end{array}$ \\
\hline
\end{tabular}

ning objects. These efforts are oriented to the description of learning objects with metadata and to the production of specifications and guidelines of content aggregation, run-time environment, navigation sequencing and tracking of the learner progression. All these efforts aim to specify and standardize e-learning objects and contents in order to be accessible, interoperable, durable and reusable [1].

SCORM, the de-facto E-learning content reference model, propose a model that is based on the following widely adopted concepts and specifications (SCORM 2004, 2nd Edition [5]): Sharable Content Object (SCO), The SCORM Content Aggregation 
Model (CAM), The SCORM Run Time Environment (RTE) and The SCORM Sequencing and Navigation (SN).

Learning Object Metadata (LOM) specification (Of IEEE) defines the following nine categories for metadata of a learning object: General, Life Cycle, Meta-Metadata, Technical, Educational, Rights, Relation, Annotation and Classification. These categories are illustrated with their sub-elements in figure 2.

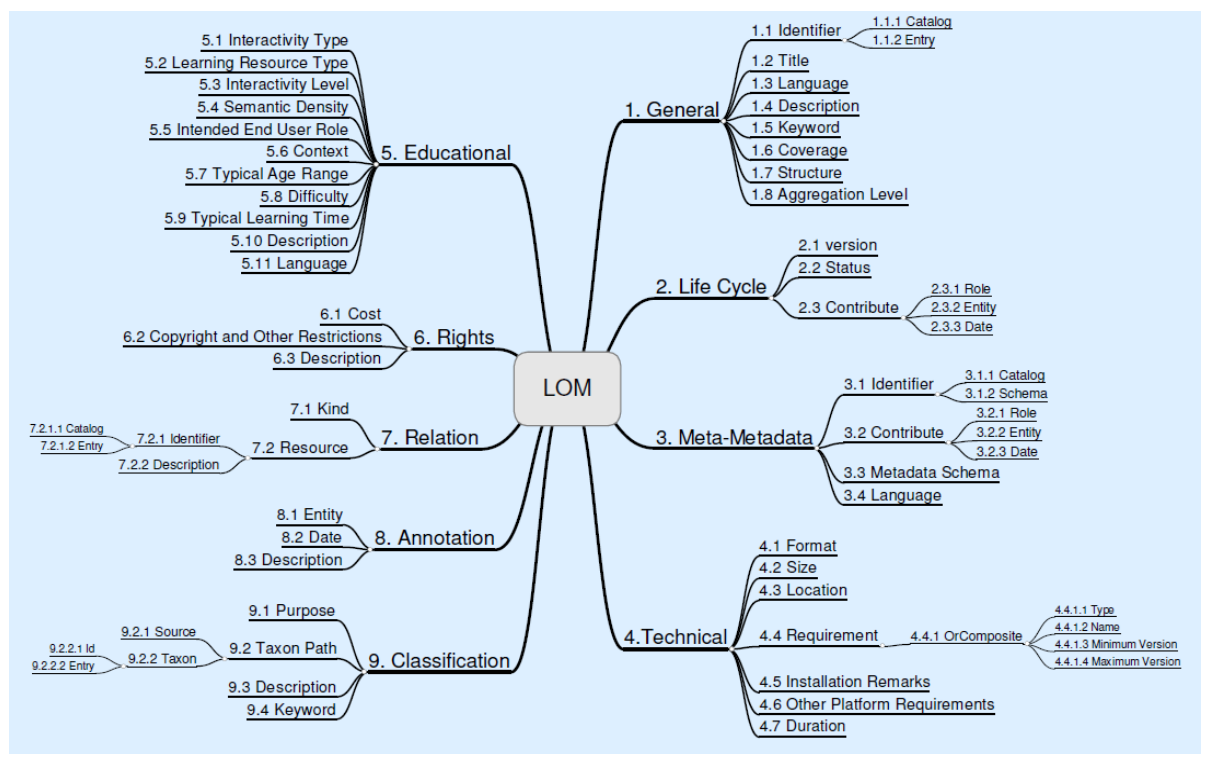

Fig. 2. A schematic representation of the hierarchy of elements in the LOM data model $\left(\right.$ WhatIsLOM $^{5}$ )

On the other side, simulation software industry had produced software, experimental frames and modeling tools along last decades. Efforts have been deployed by research and the industry consortia and government organizations. High Level Architecture (HLA) was developed for DoD (United States Department of Defence). The latter reference model and the IEEE Standard 1516-2000[6] are widely used for implementing distributed simulation to improve reusability and interoperability between these software and frames and to support simulation data interchange. Most of these efforts have focused on the runtime information flows to support distributed interactive simulation for defense and military purposes. The main leitmotiv for these researches was the improvement of the system quality, development cycles and cost reduction (Ingalls, 1986[7]). The same motivation was shared by other industry consortia and organizations aiming to improve reusability and interoperability between Elearning software and templates (LMS, Web) and to standardize shareable Content objects (ADL's SCO/SCORM). These latter efforts, but also recent research on learning and training approaches, recognize the growing role of simulation activities in

${ }^{5}$ http://metadata.cetis.ac.uk/guides/WhatIsLOM.pdf 
learning process especially in high risk training environment and decision making skills transfer [1]. Thus the use of simulations as a training tool has increased significantly over the two last decades. However, each of these standards, HLA and SCORM, independently focuses separately on reusability and interoperability of simulations and instructional content (respectively). Little research effort has been deployed on developing reusable simulation based E-Learning content [1].

A part from, some application and publication very specific to defense and military learning and training domain, there has been little progress towards developing standards and specifications that conforms simulation objects models with the E-Learning standard object models such as SCORM's SCO in higher education and workplace [1]. The main and recent initiatives were SCORM (SCORM 2.0 next generation ) and Common Cartridge . But as deep as is our literature review, the main objective of these efforts is to allow simulators or simulation software or simulation models (or objects) to retrieve information from the LMS, to run on the LMS environment and to track simulation information as well as learner progress to the LMS. This interchange could be sought also from E-learning point of view, as a requirement for E-learning contents; using simulation activities as a supplement activity; where the instructor may need to embed a simulator or a simulation model which is compliant with the LMS (or SCORM, the de-facto standards for nowadays LMS) and suitable for learning content sequencing [1].

The main obstacle to these efforts is the approach (or attempt of conceptualization) of "simulation objects" as "SCO". In fact, Simulation objects are either [1]:

- Considered to be learning objects (SCO). Most of the specifications used in SCORM consider SCO's as the smallest unit of information you can deliver; to your learners via an LMS; to track student performance or interaction. More over, it should be a URL-launchable asset when called by the learner on the LMS. All this is applicable for game and initially parameterized simulation but not for the wide simulation usage.

- Or they were considered as external learning resources (assets or activities) for which specific applications (or applets...) were developed to set their launch, initialization and tracking from SCORM conformant LMS. However, these methods could not be generalized to simulation wide usage because they require other specific software and applets to be installed and configured manually for the particular situation. This doesn't serve well standardization objective.

LOM metadata model had been enriched and diverged to several LOM application profiles attempting to adapt LOM to specific contexts, new or specific Learning Objects (LOs) or specific learning cultures. We do not aim any of these axes. Our purpose is to contribute in enriching LOM with attributes that will enforce its coverage and maintain its standardization benefit for LOs that are widely and universally used in most widely accepted contexts. Our literature review of recent advancements in simulation showed; in one hand; that the simulation based LOs are more and more widely used and that these LOs have specific characteristics that deserve the enrichment of LOM model to take them into account. Also, higher engineering education and workplace use more complex Learning objects which require another specifica- 
tion [1]. On the other hand, actual Metadata model LOM, cover a wide range of LOs classes (Text presentation, media, demonstrations...) which are mainly based on static content [8].Though, It represents lacks of deep descriptions of the dynamic aspects of simulation objects and its incremental aspects. Instead of trying to integrate simulation in E-learning contents by using more and more communication applets and interfaces (going sometime in the opposite direction of standardization), it is better to enrich LOM model with sub-elements and values that will cover specific aspects of simulation objects [1]. More over, simulation object escape IEEE definition as well as almost all definitions given to Learning Object. The closest one to what is simulation object was given by Merrill, 2000 [9]: "Combined knowledge object and a strategic object representing a mental model to be developed by a learner through incremental elaboration". El Saddik \& al 2000 [8] had suggested another category (Dynamic metadata) as expansion to LOM model for "Smart Learning Object", simulation among others.

Our proposal in laaziz et al 2013 [1] maintained the same nine (9) LOM categories and made proposals for metadata sub-elements (and sub-elements values) that used some HLA's Simulation Object Model (SOM) attributes. In this proposal, we found converging points in defining SOM and LOM and enriched Life cycle, Educational and technical categories with sub-elements that might be more descriptive for simulation LOs. Table.2 reflects these sub-elements suggestions.

\subsection{Constructivism, simulation and E-learning content models}

Simulation activity is recognized to be the closest way of learning to the "learning by doing" and "learning by experience" concepts which are emphasized by constructivism and social constructivism approaches. Works of (Piaget 1923[10], Dewey1938 [11], Kolb \& Fry 1975[12]) recognized the active role of the trainee (or learner) to give sense and direction to the learning experience. This target is central in simulation usage in higher education and workplace training.

On the other hand, simulation is recognized to have a great impact on skills transfer especially because of its incremental and experiential aspect. In ADL's "DesigningSimulation-Training-to-Foster-Transfer" [13], we found cycle of experiential learning and transfer from simulations (Hahn's, 2010) [14], that says more about learning and transfer from simulations.

There is a wide use of simulation in these areas for class or lab training but remains less used in E-learning content. To have E-learning contents very conformant to constructivist approach (as well as Social constructivist one), there should be more integration between simulation activities (and reference models) and E-learning content reference models and easiness for learner to switch between simulations activity and the other E-learning contents beyond the LMS (Laaziz et al 2013[1]). stand-alone applications are incompatible with typical production, distribution, and usage patterns for educational software [15]. 
Table 2. LOM model update proposal [1]

\begin{tabular}{|c|c|c|c|}
\hline Category & $\begin{array}{l}\text { Sub-element } \\
\text { Or added Sub-element }\end{array}$ & $\begin{array}{l}\text { Sub- element } \\
\text { Sufficiency or } \\
\text { added }\end{array}$ & additional values \\
\hline \multirow[t]{2}{*}{ 1.General } & 1.7 Structure & Insufficient & - incremental \\
\hline & $\begin{array}{l}\text { Technology } \\
\text { technology) }\end{array}$ & Added & $\begin{array}{ll}\text { - } & \text { static } \\
\text { - } & \text { dynamic }\end{array}$ \\
\hline \multirow[t]{2}{*}{ 2.Life Cycle } & 2.2 Status & Insufficient & $\begin{array}{l}\text { - End user parameterized (or } \\
\text { customized) }\end{array}$ \\
\hline & 2.3.1 Con tribute.role & Insufficient & - $\quad$ Modeler (or model designer) \\
\hline 3.Meta-MetaData & All & sufficient & None \\
\hline \multirow[t]{3}{*}{ 4.Technical } & $\begin{array}{l}\text { 4.4.1.1 Requirement. } \\
\text { Orcomposite. type }\end{array}$ & Insufficient & - HLA interface \\
\hline & $\begin{array}{l}\text { 4.4.1.2 Requirement. } \\
\text { Orcomposite. name }\end{array}$ & Insufficient & $\begin{array}{l}\text { - access to HLA' RTI (Run Time } \\
\text { Infrastructure) }\end{array}$ \\
\hline & Dimen sion & Added & $\begin{array}{l}\text { - } 2 \mathrm{D}(2 \text { dimension }) \\
\text { - } 3 \mathrm{D} \\
\text { (Or x,y\& } \mathrm{z} \text { as stated in } \\
\text { El Saddik \& al, 2000) }\end{array}$ \\
\hline \multirow[t]{4}{*}{ 5.Educational } & 5.1 In teractivity type & Insufficient & 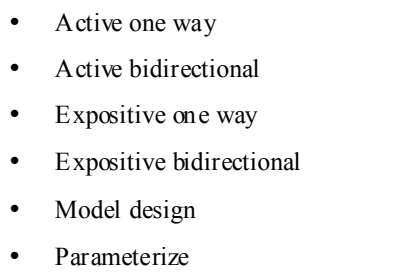 \\
\hline & $\begin{array}{l}5.2 \text { Learning Resource } \\
\text { Type }\end{array}$ & Insufficient & $\begin{array}{l}\text { Instead of Simulation value: } \\
\text { - } \quad \begin{array}{l}\text { Animation (or parameterized } \\
\text { simulation) }\end{array} \\
\text { - } \quad \text { Simulation (Un-parameterized) }\end{array}$ \\
\hline & $\begin{array}{l}5.5 \text { Intended End user } \\
\text { Role }\end{array}$ & Insufficient & - Modelling Learner \\
\hline & 5.6 Context & Insufficient & - Work place training \\
\hline 6.Rights & All & sufficient & None \\
\hline 7.Relations & All & Sufficient & None \\
\hline 8.Annotation & 8.3 Description & in sufficient & $\begin{array}{l}\text { LOM Data type for Description: } \\
\text { should be able to contain a synthesis } \\
\text { on simulation activity: }\end{array}$ \\
\hline
\end{tabular}




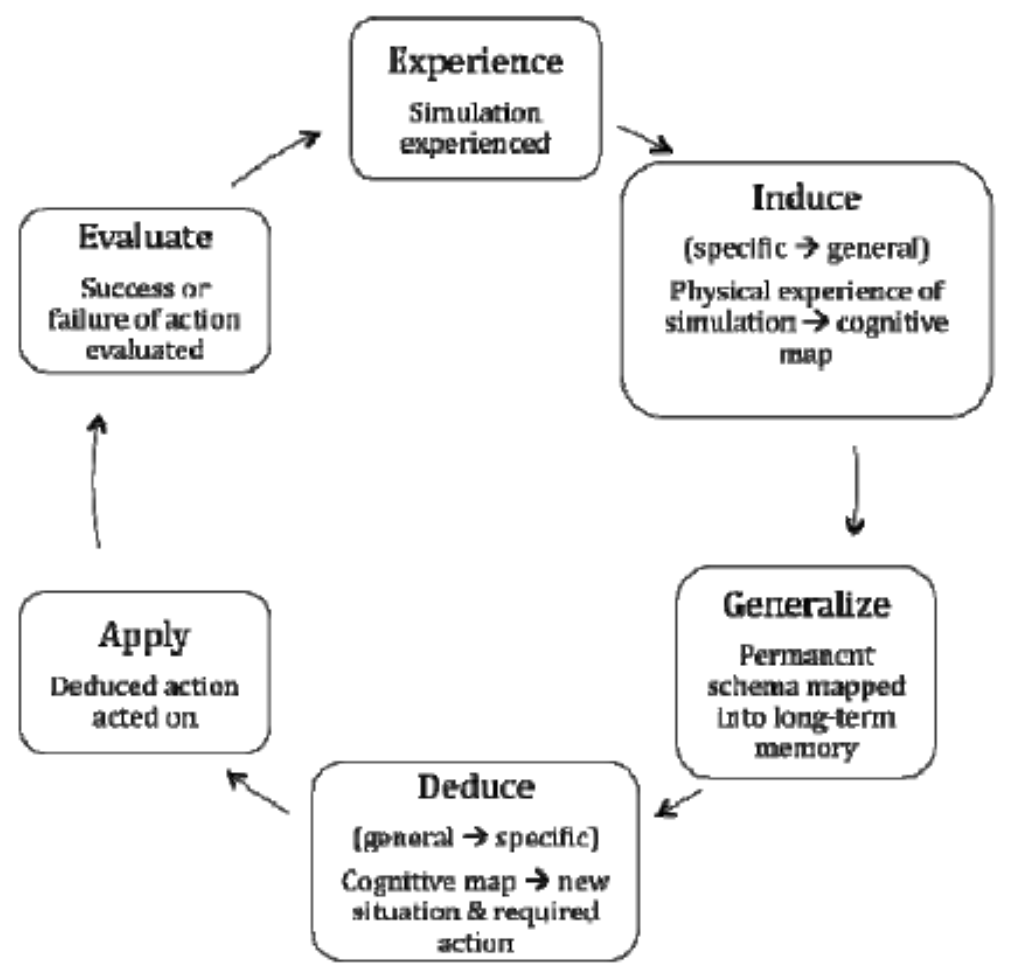

Fig. 3. Hahn's (2010) cycle of experiential learning and transfer from simulations

\section{Our improvement proposal for LOM specification}

The word The specification update suggested in Laaziz et al 2013 [1], coupled with our recent literature review in term of advancement in simulation for higher education (see Horton 2000[3], and Brandon 2002 [2]), had driven us to review and assess LOM model completeness and its coverage of simulation based learning objects. The main updates suggestions concern LOM categories, 5.Edacational and 6.Rights and are:

a) 5.2 Learning Resource Type: this Sub element value "Simulation" is very restrictive against the very wide range of simulation based learning resources. In this wide range we found very divergent kinds of simulation based LOs in term of targeted learnees, pedagogic objectives and learning methods. The following values are suggested instead:

- Animation (or parameterized simulation)

- one-shot simulation

- learn by example simulation

- microworld simulation

- serious game 
b) 5.5 Intended End user Role: we added an additional value "By experience learner" for the sub-element. This user role is to be separated from the general role "learner" as learning by experience LOs are generally different, especially simulation based ones.

c) 5.12 pedagogic/andragogic purpose: is an added sub-element. The reasons for this addition are:

- The multiplication of LOM application profiles nowadays is generally justified by the intention to adapt LOM to support E-learning contents with pedagogic or cultural specificities. In contrast, we found it paramount to allow characterisation of pedagogic (or andragogic) aspect of LO in LOM in order to remain in standardization direction.

- Simulation based LOs; especially as they are by experience or practical oriented and very close to real life reality; need to be pedagogically characterized.

We proposed, thus, the following values:

- knowledge

- Business

- Situational

- Relational

- Procedural

d) 6.1 Cost sub-element of (6.Rights) had to be more detailed with additional values. In LOM specification two values (yes/no) are established. As simulation Learning objects are at least a medium complex software necessarily costing and because their usage pricing is in close relation with usage mode (which it self had an impact on pedagogic targets), we suggest the following values for Rights.Cost:

- yes/ off-the-shelf

- Yes/license

- Yes/per user

- Yes/ per course

- no

In Table 3, we summarize the main improvement proposal.

\section{Conclusion and perspectives}

In this article, our purpose was to contribute deeply in the adaptation of LOM metadata model to simulation based learning object. Our review of existing E-learning specifications and standards as well as standardization initiatives of the simulation industry showed that that there is a compliance gap between these existing specification and the widely accepted characteristics of simulation based learning objects.

We come to the conclusion that, E-learning specification for LMS and Meta-data models should be enriched with additional sub elements and values compliant with 
simulations learning objects. We developed and suggested a new metadata model focussing on educational aspects on the basis of LOM model.

In our future researches, we will continue on enriching LOM model not only regarding the simulation learning objects, but also regarding specific learning objects to experiential learning.

Table 3. Our proposal for lom metadata

\begin{tabular}{|c|c|c|c|}
\hline Category & $\begin{array}{l}\text { Sub-element } \\
\text { Or added Sub-element }\end{array}$ & $\begin{array}{l}\text { Sub- element } \\
\text { Sufficiency or } \\
\text { added }\end{array}$ & additional values \\
\hline \multirow[t]{2}{*}{ 1.General } & 1.7 Structure & Insufficient & - incremental \\
\hline & $\begin{array}{l}\text { Technology (or base } \\
\text { technology) }\end{array}$ & Added & $\begin{array}{ll}\text { - } & \text { static } \\
\text { - } & \text { dynamic }\end{array}$ \\
\hline \multirow[t]{2}{*}{ 2.Life Cycle } & 2.2 Status & Insufficient & $\begin{array}{l}\text { End user parameterized (or } \\
\text { customized) }\end{array}$ \\
\hline & 2.3.1 Con tribute.role & Insufficient & - $\quad$ Modeller (or model designer) \\
\hline 3.Meta-MetaData & All & sufficient & None \\
\hline \multirow[t]{3}{*}{ 4.Technical } & $\begin{array}{l}\text { 4.4.1.1 Requirement. } \\
\text { Orcomposite. type }\end{array}$ & Insufficient & - HLA interface \\
\hline & $\begin{array}{l}\text { 4.4.1.2 Requirement. } \\
\text { Orcomposite. name }\end{array}$ & Insufficient & $\begin{array}{l}\text { - access to HLA' RTI (Run Time } \\
\text { Infrastructure) }\end{array}$ \\
\hline & Dimension & Added & $\begin{array}{l}\text { - } 2 \mathrm{D} \text { (2 dimension) } \\
\text { - } \quad 3 \mathrm{D} \\
\text { (Or x,y\& } \mathrm{z} \text { as stated in } \\
\text { E1 Saddik \& al, 2000) }\end{array}$ \\
\hline \multirow[t]{4}{*}{ 5.Education al } & 5.1 In teractivity type & Insufficient & $\begin{array}{ll}\text { - } & \text { Active one way } \\
\text { - } & \text { Active bidirectional } \\
\text { - } & \text { Expositive one way } \\
\text { - } & \text { Expositive bidirectional } \\
\text { - } & \text { Model design } \\
\text { - } & \text { Parameterize }\end{array}$ \\
\hline & $\begin{array}{l}5.2 \text { Learning Resource } \\
\text { Type }\end{array}$ & Insufficient & $\begin{array}{l}\text { Instead of Simulation value: } \\
\text { - Animation (or parameterized } \\
\text { simulation) } \\
\text { - } \quad \text { one-shot simulation } \\
\text { - learn by example simulation } \\
\text { - microworld simulation } \\
\text { - } \quad \text { serious game }\end{array}$ \\
\hline & $\begin{array}{l}5.5 \text { Intended End user } \\
\text { Role }\end{array}$ & Insufficient & $\begin{array}{l}\text { - } \quad \text { Modelling Learner } \\
\text { - By experience learner }\end{array}$ \\
\hline & 5.6 Context & Insufficient & - Work place train ing \\
\hline
\end{tabular}




\section{$5 \quad$ References}

[1] Laaziz, E. H., Elkhouzai, E., \& Nassereddine, B. (2013). PROPOSITION OF A CONTENT MODEL FOR SIMULATION BASED E-LEARNING. EDULEARN13 Proceedings, 6664-6672.

[2] Brandon-hall.com. (2002). E-Learning Simulations: Tools and Services for Creating Software, Business, and Technical Skills Simulations. Executive Summary. Retrieved March 18, 2002 from the World Wide Web: http://www.brandonhall.com/simulations.html

[3] Kolb, D. (1984). Experiential learning: Experience as the source of learning and development. Englewood Cliffs, NJ: Prentice-Hall.

[4] Horton, W. K. (2000). Designing web-based training: How to teach anyone anything anywhere anytime (Vol. 1). New York, NY: Wiley.

[5] SCORM 2004, 2nd Edition. http://scorm.com/

[6] IEEE Std 1516.2-2000. http://ieeexplore.ieee.org

[7] Ingalls, R. G. (1986). Automatic Model Generation. Proceedings of the 1986 Winter Simulation Conference. https://doi.org/10.1145/318242.318509

[8] El Saddik.A, Ghavam.A, Fischer.S, Steinmetz.R (2000). Metadata for Smart Multimedia Learning Objects.

[9] Merrill, M. D. (2000). Knowledge objects and mental models. In D. A. Wiley (Ed.), The Instructional Use of Learning Objects. http://reusability.org/read/chapters/merrill.doc.

[10] Piaget, J. (1923). Le langage et la pensée chez l'enfant. Neuchâtel et Paris : Delachaux et Niestlé, 3ème éd., 1966

[11] Dewey, J. (1938). Experience and education. New York: Collier.

[12] Kolb. D. A. and Fry, R. (1975). Toward an applied theory of experiential learning. In C. Cooper (ed.).Theories of Group Process, London: John Wiley.

[13] ADL (2010). Designing Simulation Training to Foster Transfer. http://www.adlnet.gov/wp-content/uploads/2011/07/Designing-Simulation-Training-toFoster-Transfer.pdf

[14] Hahn, S. H. (2010). Transfer of training from simulations in civilian and military workforces: Perspectives from the current body of literature. Unpublished manuscript.

[15] Roschelle, J., \& Kaput, J. (1996). Educational software architecture and systemic impact: The promise of component software. Journal of Educational Computing Research, 14(3), 217-228. https://doi.org/10.2190/YLTR-MLTH-WKE8-L9G3

\section{Authors}

El Hassan Laaziz is with IDDS/FSTS at Hassan 1st University, Settat, Morocco (laaziz02@gmail.com).

Elmustapha Elkhouzai is with IDDS/FSTS at Hassan 1st University, Settat, Morocco (elkhouzai_m@yahoo.fr).

Article submitted 17 October 2016. Published as resubmitted by the authors 23 December 2016. 